Pesq. Vet. Bras. 30(8):676-684, agosto 2010

\title{
Morfologia do tubo digestório da tartaruga verde (Chelonia mydas) $^{1}$
}

\author{
Marcela S. Magalhães ${ }^{2 *}$, Maria de Lourdes Freitas ${ }^{3}$, Naisandra B. da Silva ${ }^{3}$ \\ e Carlos Eduardo B. de Moura ${ }^{3}$
}

\begin{abstract}
Magalhães M.S., Freitas M.L., Silva N.B. \& Moura C.E.B. 2010. [Morphology of the digestive tube of the green turtle (Chelonia mydas).] Morfologia do tubo digestório da tartaruga verde (Chelonia mydas). Pesquisa Veterinária Brasileira 30(8):676-684. PósGraduação em Biologia de Água Doce e Pesca Interior, Instituto Nacional de Pesquisas da Amazônia, Av. André Araújo 2936, Cx. Postal 478, Aleixo, Manaus, AM 69011-970, Brazil. E-mail: marcelasmbio@gmail.com

The morphology of the digestive tube of the green turtle (Chelonia mydas) was evaluated. Nine young e 1 adult turtles were analyzed. The digestive organs withdrew occurred after plastron opening. The length's description and measurement from each organ [esophagus, stomach, small intestine (SI) and large intestine (LI)] were made with digestive tube opened. The results showed that in both the adult and young animals, the esophagus from all species were marked by the presence of pointed papillae on internal mucous. The stomach presented saclike shape with blind fund. In the SI, reticular pleats in the duodenal mucous membrane have been observed, while the jejune and the ileum showed rectilinear longitudinal pleats. The LI was marked by the alternation of arched areas (haustra or sacculations) and narrowings. The microscopy of digestive tube from $C$. mydas revealed esophagus with folded mucous covered by keratinized and stratified squamous epitheliums. The stomach was divided in regions: cardiac, fundic e pyloric which differed as to the number of glands and the muscle layer's arrangement. The SI presented marked by microvillus, and LI by folded mucous with glands the lamina propria. The morphology of the tube digestive of the green turtle showed to be adapted to your eating habits. A long the digestive tract and specializations provide greater area of absorption and more efficiency in digestion in this species.
\end{abstract}

INDEX TERMS: Anatomy, digestive apparatus, sea turtle.

RESUMO.- Para avaliar a morfologia do tubo digestório da tartaruga verde (Chelonia mydas) 10 animais, 9 juvenis e 1 adulto, foram analisados. A retirada dos órgãos digestórios procedeu-se após abertura do plastrão. A descrição e a medida do comprimento de cada órgão [esôfago, estômago, intestino delgado (ID) e intestino grosso (IG)] foram realizadas com o tubo digestório aberto. Os resultados mostraram que tanto nos animais juvenis como no adulto,

\footnotetext{
${ }^{1}$ Recebido em 23 de novembro de 2009.

Aceito para publicação em 5 de março de 2010.

2 Pós-Graduação em Biologia de Água Doce e Pesca Interior, Instituto Nacional de Pesquisas da Amazônia, Av. André Araújo 2936, Cx. Postal 478, Aleixo, Manaus, AM 69011-970, Brasil. *Autor para correspondência: marcelasmbio@gmail.com

${ }^{3}$ Departamento de Morfologia, Universidade Federal do Rio Grande do Norte, Cx. Postal 1524, Campus Universitário Lagoa Nova, Natal, RN 59072-970, Brasil.
}

o esôfago foi marcado pela presença de papilas pontiagudas em sua mucosa interna. O estômago apresentou aspecto saculiforme com fundo cego. No ID foi observado pregas reticulares na mucosa duodenal, enquanto o jejuno e do íleo mostrou pregas retilíneas longitudinais. O IG foi marcado pela alternância de regiões abauladas (haustros ou saculações) e estreitamentos. A microscopia do tudo digestório em C. mydas revelou esôfago com mucosa pregueada revestida por epitélio estratificado pavimentoso queratinizado. $O$ estômago mostrou-se dividido em regiões: cárdica, fúndica, pilórica, as quais diferiam quanto ao número de glândulas e disposição da camada muscular. $\mathrm{O}$ ID apresentou-se marcado por vilosidades, e o IG por mucosa pregueada contendo glândulas na lâmina própria. $A$ morfologia do tubo digestório da tartaruga verde mostrouse adaptada ao seu hábito alimentar, possuindo especializações e um longo trato digestório que promove o aumen- 
to da superfície de absorção, já que seu alimento é de difícil digestão.

TERMOS DE INDEXAÇÃO: Anatomia, aparelho digestório, tartaruga marinha.

\section{INTRODUÇÃO}

As tartarugas marinhas estão agrupadas em duas famílias: Dermochelyidae e Cheloniidae. Das sete espécies existentes, seis são encontradas no atlântico e de acordo Sanches (1999) apenas cinco delas podem ser encontradas na extensão do litoral brasileiro, são elas: a tartaruga verde (Chelonia mydas), tartaruga de pente (Eretmochelys imbricata), tartaruga oliva (Lepidochelys olivacea), tartaruga cabeçuda (Caretta caretta) e a tartaruga de couro (Dermochelys coriacea). A tartaruga verde é a mais comum no litoral brasileiro (Fidelis et al. 2005). No Brasil essa espécie desova nas ilhas oceânicas, como Fernando de Noronha, Trindade e Atol das Rocas (Marcovaldi \& Marcovaldi 1985). Particularmente, o Rio Grande do Norte, é considerado uma importante área de alimentação dessa espécie (Santos et al. 2006).

A tartaruga verde é a única tartaruga marinha herbívora (Brand-Gardner et al. 1999). Supõem que essa espécie na sua fase pelágica é onívora com uma forte tendência carnívora, tornando-se basicamente herbívora em sua fase juvenil a adulto (Chevalier \& Lartiges, 2001, Fidelis et al. 2005). Segundo Bjorndal (1997), a partir dos 25 a 35cm de Comprimento Curvilíneo da Carapaça (CCC) essa espécie inicia uma alimentação herbívora. Em um estudo realizado por Ferreira (1968) no estado do Ceará, as algas marinhas bentônicas constituíram o alimento básico da Chelonia mydas, presente em $88,30 \%$ dos estômagos analisados. Apesar de apresentarem uma dieta primariamente herbívora, ocasionalmente essas tartarugas consomem invertebrados (Seminoff et al. 2002). Castell et al. (2005) sugere que, dados os baixos valores de abundância de itens de invertebrados, presume-se ser um consumo incidental, devido a sua associação com espécies de algas. A dieta herbívora tem importante conseqüência para os parâmetros da história de vida e probabilidade de sobrevivência das tartarugas verdes, e essa espécie apresenta importante efeito na ciclagem de nutrientes e na estrutura da comunidade de algas em seu habitat de alimentação (Bjorndal 1997).

Embora o conhecimento da biologia e ecologia de tartarugas esteja sendo ampliado, a nível mundial, estudos morfológicos ainda são incipientes. Estes estudos relacionados ao sistema digestório demonstram que sua morfologia está intimamente relacionada aos hábitos alimentares (Silva 2004). Ainda neste raciocínio Luz et al. (2003) defendem que estudos de parâmetros morfométricos do trato gastrintestinal se fazem necessários para fornecer subsídios sobre os processos digestórios dos alimentos no organismo animal e indicar a preferência alimentar de uma espécie.

Estudos anatômicos e morfométricos fornecem informações importantes para clínica de animais silvestres (Pinto 2006). Esses estudos juntamente com exames complementares como endoscopia, colonoscopia e radiografia podem ser conduzidos em quelônios, com finalidade de elucidar fenômenos fisiológicos e patológicos do trato gastrintestinal (Meyer 1998). No entanto, Holt (1978) complementa que essas pesquisas em répteis ainda são insuficientes, embora haja uma utilização maior em quelônios, principalmente nas avaliações de obstruções gastroentéricas por corpos estranhos, devido, por exemplo, a ingestão acidental de lixo que ocorre com espécies de tartarugas marinhas, como verificado por Silva et al. (2007) em um espécime de Chelonia mydas e Lepdochelys olivacea.

A grande variedade de répteis tem exigido mais esforços para compreender as particularidades da anatomia de cada espécie, com valor econômico e de conservação (Costa et al. 2009). Portanto é de grande importância que se conheça a descrição da localização dos órgãos digestórios na cavidade celomática, para realização corretas dos diversos exames e cirurgias sem prejuízo algum aos órgãos.

Segundo Pessoa et al. (2008) as técnicas cirúrgicas tradicionais com acesso a cavidade celomática por remoção parcial do plastrão, é um processo muito traumático, podendo injuriar estruturas adjacentes ou órgãos internos. Os mesmo autores demonstraram em tartarugas-de-ouvido-vermelho que a técnica da ooformia assistida por acesso pré-femoral mostrou que além da localização rápida e atraumática dos folículos, a utilização do endoscópio permitiu também uma inspeção detalhada da cavidade celomática e seus órgãos.

De acordo com a Lista Nacional das Espécies da Fauna Brasileira Ameaçada de Extinção (Ministério do Meio Ambiente 2005), as cinco espécies de tartarugas marinhas encontradas no litoral brasileiro continuam incluídas como animais ameaçados. Por isso qualquer informação acerca da morfologia dessa espécie é importante, mesmo utilizando um pequeno número de animais. Assim, apenas pelo conhecimento dos aspectos quantitativos da dieta selecionada, dos processos digestivos, e da nutrição pode ser possível entender qual a função das tartarugas marinhas no ecossistema marinho (Bjorndal 1997). Desse modo conhecendo-se aspectos, ainda que básicos, desse processo, somam-se aos esforços para a conservação das tartarugas marinhas.

Diante do exposto, este trabalho tem como objetivo analisar a morfologia do tubo digestório das tartarugas verdes, relacionando-o com sua dieta alimentar. Fornecendo assim, subsídios para a compreensão da fisiologia da digestão desses animais.

\section{MATERIAL E MÉTODOS}

Foram utilizados neste estudo 10 tartarugas verdes, 9 juvenis e 1 adulta encontradas mortas no litoral do Rio Grande do Norte e que morreram durante período de reabilitação no Aquário Natal, doados pelo o Projeto TAMAR/ICMBio (Licença $n^{\circ}$ 006/05 IBAMA-RN). O estudo ocorreu durante o período de janeiro de 2006 a outubro de 2007.

Biometria das tartarugas. Realizou-se a biometria de todos os espécimes estudados, sendo registrados os dados individuais referentes ao comprimento curvilíneo da carapaça (CCC) (do ponto médio anterior do escudo nucal ao extremo das placas supracaudares) e largura curvilínea da carapaça 


\begin{tabular}{|c|c|c|}
\hline \multicolumn{3}{|c|}{$\begin{array}{c}\text { Quadro 1. Médias do comprimento curvilíneo } \\
\text { da crapaça (CCC) e largura curvilínea da } \\
\text { crapaça (LCC) (em cm) de Chelonia mydas. } \\
\text { Natal, } 2007\end{array}$} \\
\hline \multicolumn{3}{|l|}{ Faixa etária ${ }^{a}$} \\
\hline \\
\hline & & \\
\hline
\end{tabular}

a $\mathrm{J}=$ juvenil, $\mathrm{A}$ = adulto.

(LCC) (Bolten 2000, Work 2000). A medição foi realizada com fita métrica e os dados descritos em centímetro.

Os dados referentes ao CCC e LCC dos animais analisados neste estudo encontram-se descritos no Quadro 1.

Análise morfológica e morfométrica do tubo digestório. Os animais foram dissecados no laboratório de Anatomia Animal do Departamento de Morfologia - UFRN de acordo com a metodologia utilizada por Work (2000), possibilitando análise de características morfológicas externas e internas do tubo digestório. A retirada dos órgãos digestórios procedeu-se através da abertura do plastrão, com posterior remoção dos músculos peitorais, das clavículas e da cintura pélvica. Para o estudo interno dos órgãos as partículas alimentares foram removidas para facilitar a visualização. O comprimento de cada órgão (esôfago, estômago, intestino delgado e intestino grosso) foi realizado com o tubo digestório aberto, levando em consideração a presença de papilas, esfíncteres e disposição das pregas da mucosa. Em seguida, foi feita a descrição morfológica de cada órgão, sendo observada a presença ou não, e se presentes a forma das papilas, tipo e a disposição das pregas da mucosa, e presença de esfincteres. Ao fim de cada análise, o material foi devidamente etiquetado e fixado em solução aquosa de formol a $10 \%$.

Processamento e análise histológica. Para as análises histológicas foram utilizados os animais que vieram a óbito no Centro de Reabilitação do Aquário Natal. Após necropsia, fragmentos de $0,5 \mathrm{~cm}^{3}$ foram obtidos do esôfago, das palipas esofágicas, do estômago, intestino delgado (regiões referentes ao duodeno, jejuno e íleo) e do intestino grosso de 4 espécimes de Chelonia mydas. Logo após foram fixados em solução de Bouin por 24 horas. Após este período foram submetidos às técnicas histológicas de rotina (desidratação, diafanização e inclusão em parafina), seguindo metodologia proposta por Maia (1979). Cortes de $5 \mu \mathrm{m}$ foram preparados em micrótomo antes de serem submetidos à coloração por hematoxilina-eosina (Maia 1979). Posteriormente as lâminas confeccionadas foram observadas ao microscópio de luz, e microfotografadas para análises e comparações em microscópio com câmara digital, ambos acoplados a um microcomputador.

\section{RESULTADOS}

O tubo digestório da todas as tartarugas verdes analisadas encontrou-se, basicamente dividido em esôfago, estômago, intestino delgado e intestino grosso.

\section{Esôfago}

O esôfago das tartarugas verdes analisadas apresentou-se como um órgão tubular muscular. A mucosa esofágica mostrou-se marcada por papilas pontiagudas córneas, as quais se encontravam orientadas no sentido do estômago, tornando-se gradativamente maiores na direção da região caudal do esôfago (Fig.1A). O comprimento médio do esôfago está descrito no Quadro 2.

Histologicamente, o esôfago, apresentou mucosa pregueada constituída por epitélio estratificado pavimentoso queratinizado (Fig.2A,B), com lâmina própria aglandular, formada por tecido conjuntivo frouxo. Não foram evidenciadas muscular da mucosa e submucosa. A camada muscular foi formada por musculatura estriada organizados em feixes em uma única camada, dispostos longitudinalmente contendo abundante tecido conjuntivo frouxo entre os feixes. A camada externa apresentou-se como adventícia na porção cranial, e serosa na porção caudal. As papilas esofágicas seguiram a mesma estrutura microscópica da mucosa esofágica (Fig.2C).

Internamente a transição esôfago-estômago foi marcada pela ausência de papilas e por um esfíncter gastresofágico (Fig.1A). Entretanto, na transição, de dois animais juvenis foi identificado à presença de um divertículo esofágico (Fig.1B), o qual apresentou mucosa desprovida de pregas, com comprimentos de 19,2cm e $37,3 \mathrm{~cm}$.

\section{Estômago}

O estômago da tartaruga verde apresentou forma de um "J" de aspecto saculiforme com fundo cego. A partir da porção caudal do esôfago, o estômago se curvou para esquerda inicialmente formando a região cárdica, em seguida formou uma grande bolsa, a região fúndica, logo ascendeu para a direita, constituindo a região pilórica (Fig.1C). Entretanto, em um animal a disposição foi diferente. A transição entre esôfago e estômago possuía forma de "S", na qual o estômago se curvava para esquerda, ascendendo, formando a região cárdia, chegando a uma grande bolsa, a região fúndica, em seguida, se curvava para a direita formando a região pilórica, ao se aproximar da primeira alça intestinal (Fig.1D). Internamente, a mucosa apresentou-se com pregas longitudinais nas regiões cárdica e pilórica, enquanto a região fúndica apresentou mucosa desprovida de pregas. O comprimento médio do estômago em $C$. mydas estão descritos no Quadro 2.

Histologicamente, o estômago apresentou glândulas túbulo-acinosas na lâmina própria em todas as regiões (Fig.2D), sendo mais numerosas no estômago fúndico e menos no estômago pilórico. Na lâmina própria foi observada a presença de tecido linfóide associado à mucosa.

\section{Quadro 2. Comprimentos médio (cm) do esôfago, estômago, intestino} delgado e intestino grosso de Chelonia mydas. Natal, 2007

\begin{tabular}{ccccc}
\hline Faixa etária $^{\mathrm{a}}$ & Esôfago & Estômago & Intestino Delgado & Intestino Grosso \\
\cline { 1 - 2 } $\mathrm{J}$ & $19,32 \pm 4,09$ & $22,37 \pm 9,08$ & $145,13 \pm 46,52$ & $238,43 \pm 54,99$ \\
$\mathrm{~A}$ & 24,70 & 78,50 & 333,20 & 1032,30 \\
\cline { 1 - 1 } $\mathrm{a}$ J = juvenil, $\mathrm{A}=$ adulto. & & & &
\end{tabular}



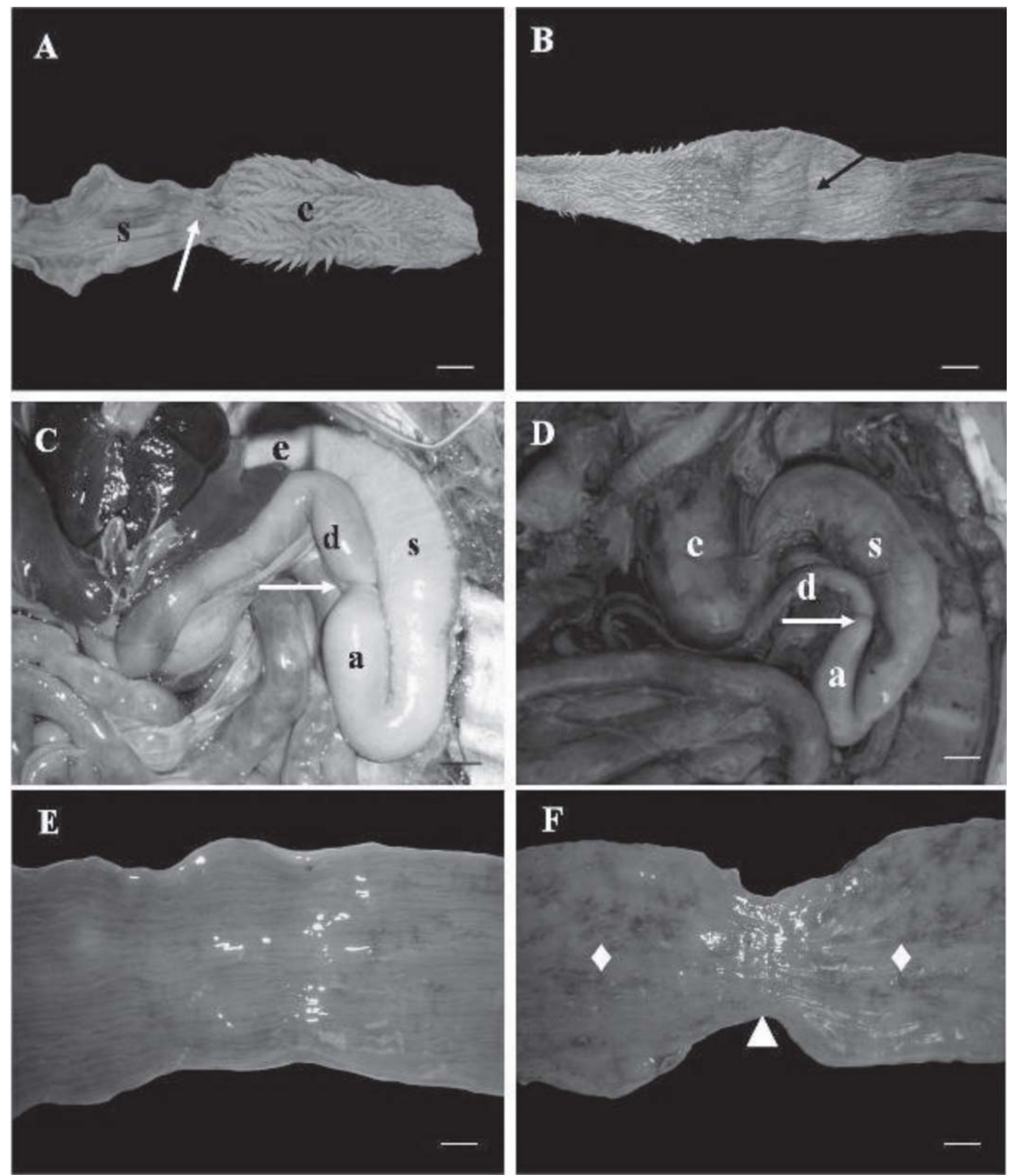

Fig.1. Tubo digestório de Chelonia mydas. (A) Mucosa interna. Esôfago com presença de papilas esofágicas; Esfíncter gastresofágico ( $\Longrightarrow$; ; estômago. (B) Divertículo esofágico aberto encontrado em dois animais juvenis de C. mydas $(\Longrightarrow)$, observar mucosa desprovida de pregas e papilas. (C) Disposição mais frequente do estômago nesta espécie. (D) Variação na disposição. Esôfago (e); estômago (s); antropiloro (a), piloro $(\Longrightarrow)$; duodeno (d). (E) Mucosa do jejuno/íleo com pregas retilíneas. (F) Intestino grosso foi marcado pela alternância de regiões abauladas $(\diamond)$ e estreitamentos $(\triangle)$. Barra: $1 \mathrm{~cm}$. 

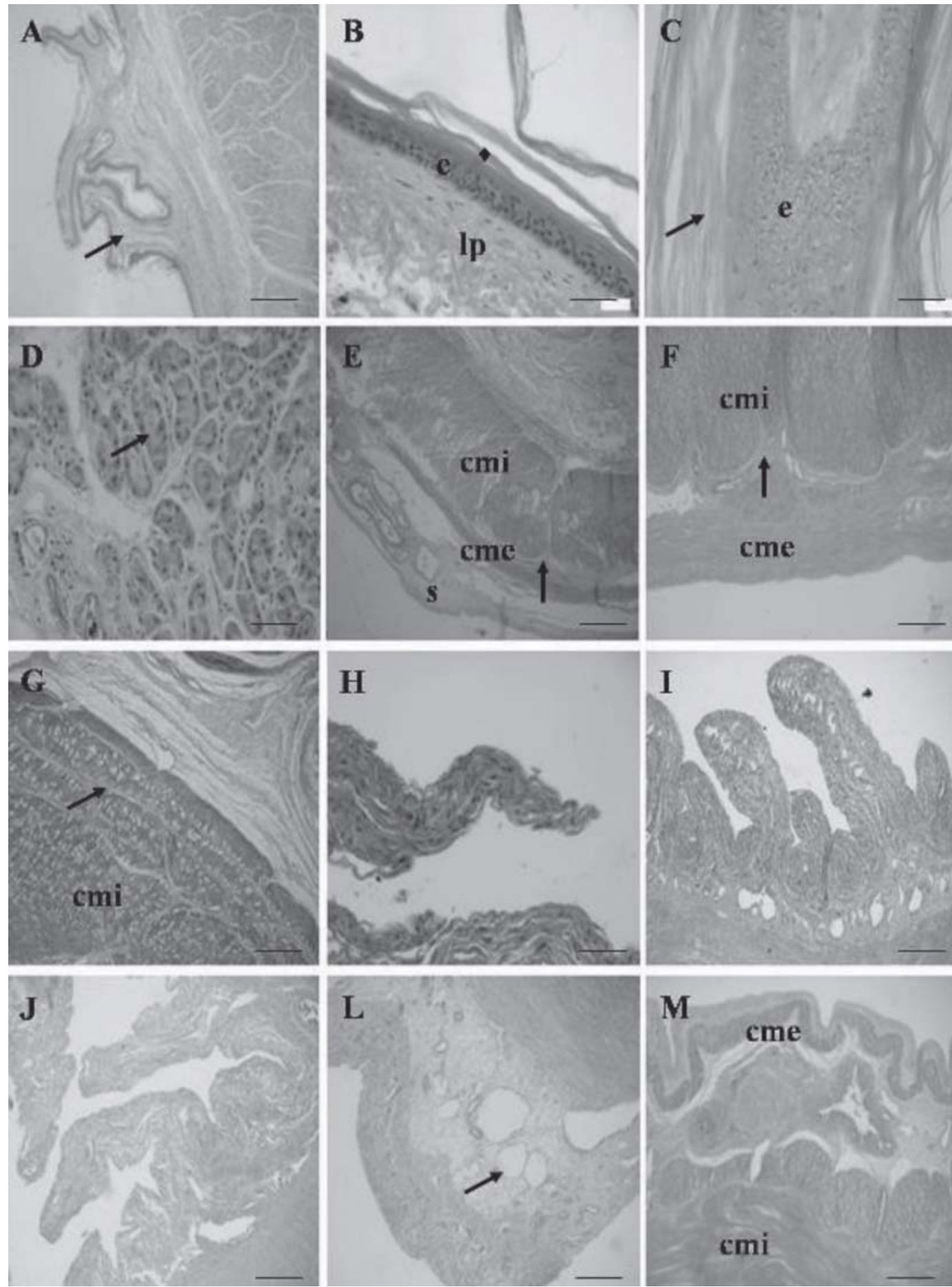

Fig.2. Órgãos do tubo digestório de Chelonia mydas. (A) Esôfago com mucosa pregueada $(\rightarrow)$. (B) Mucosa esofágica com epitélio estratificado pavimentoso (e) queratinizado ( $\bullet$ e lâmina própria (Ip). (C) Papila esofágica. Observar epitélio estratificado pavimentoso queratinizado (e) com estrato córneo espesso $(\rightarrow)$. (D) Estômago com glândulas túbulo-acinosas $(\rightarrow)$ na lâmina própria. (E,F) Camada muscular do estômago das regiões cárdica e fúndica. Observar camada circular interna (cmi); camada longitudinal externa (cme); serosa (s); feixes de tecido conjuntivo dividindo em feixes a camada muscular interna $(\rightarrow)$. (G) Camada muscular do estômago pilórico. Observar camada circular interna (cmi) e os feixes de fibras colágenas dispostas em septos que se ramificaram entre as fibras musculares lisas $(\rightarrow)$. $(\mathbf{H}, \mathbf{I}, \mathbf{J})$ Vilosidades presentes no intestino delgado. (H) Duodeno, longa e filiforme; (I) jejuno, curta e digitiforme; (J) íleo: foliada. (L) Mucosa pregueada e submucosa formada por tecido conjuntivo frouxo e vascularizada do intestino grosso. Observar vasos sanguíneos na submucosa $(\rightarrow)$. (M) Camada muscular do intestino grosso. Camada muscular circular interna (cmi); camada muscular longitudinal externa (cme). Coloração HE. Barra $=500 \mu \mathrm{m}$. 
Observou-se invaginações do epitélio de revestimento para dentro da lâmina própria, formando depressões microscópicas, chamadas fossetas gástricas, as quais se apresentaram mais profundas na região pilórica. A muscular da mucosa apresentou-se espessa formada por músculo liso. Na submucosa encontrou-se abundante rede vascular sendo formada por tecido conjuntivo frouxo. A camada muscular apresentou-se subdividida em duas camadas, uma camada circular interna e uma longitudinal externa. Na região cárdica e na fúndica, a circular interna apresentou as fibras lisas agrupadas formando feixes separados por tecido conjuntivo frouxo, sendo mais espessa na região fúndica (Fig.2E,F respectivamente), enquanto na pilórica foi observado fibras colágenas dispostas em septos que se ramificaram entre as fibras musculares lisas (Fig.2G). A muscular longitudinal foi formada por fibras lisas contínuas. Externamente foi evidenciado a presença de serosa, sendo observadas células adiposas na região cárdica.

Internamente a transição do estômago para o duodeno foi marcada por um esfíncter pilórico o qual possuía mucosa com pregas longitudinais.

\section{Intestino delgado}

$O$ intestino delgado apresentou-se dividido em 3 regiões, duodeno, jejuno e íleo. A mucosa do duodeno foi marcada pela presença de pregas reticulares com disposição semelhantes a "favos-de-mel". A passagem do duodeno para o jejuno foi marcada pela mudança na mucosa, de reticulares para retilíneas. $O$ jejuno e o íleo apresentavam pregas retilíneas justapostas (Fig.1E). A transição do jejuno para o íleo foi de difícil identificação macroscopicamente, sendo necessárias análises histológicas para confirmação. O comprimento médio do intestino delgado na $C$. midas está descrito no Quadro 2.

Histologicamente, o intestino delgado apresentou a mucosa constituída por vilosidades, sendo longa e filiforme no duodeno (Fig.2H), curta e digitiforme no jejuno (Fig.2I) e foliada no íleo (Fig.2J). Não foi possível descrever o epitélio devido ao estado de conservação do cadáver. Observou-se presença de glândulas na lâmina própria apenas no duodeno. Havia um acúmulo de linfócitos na lâmina própria do jejuno. A muscular da mucosa apresentou-se formada por fibras musculares lisas dispostas longitudinalmente. A submucosa formada por tecido conjuntivo frouxo com presença de vasos sanguíneos. A camada muscular apresentou-se subdividida em duas camadas, uma camada circular interna e uma longitudinal externa, ambas formadas por músculo liso. Externamente foi delimitado pela presença de uma serosa.

Internamente a transição do intestino delgado para o grosso se deu pela presença de um esfíncter ou válvula ileocecal em todos os animais estudados.

\section{Intestino grosso}

As regiões do intestino grosso foram de difícil identificação macroscópica, devido à ausência de limites de demarcação definidos, portanto ele foi analisado sem divisão especí- fica. O intestino grosso foi marcado pela alternância de regiões abauladas (haustros ou saculações) e estreitamentos (Fig.1F). As regiões abauladas apresentavam mucosa lisa e os estreitamentos possuíam pregas retilíneas. A região caudal, referente ao reto, foi marcado por pregas retilíneas bem evidentes. O comprimento médio do intestino grosso em $C$. mydas está descrito no Quadro 2.

Histologicamente, o intestino grosso apresentou mucosa pregueada (Fig.2L) contendo glândulas e acúmulo de linfócitos na lâmina própria. Muscular da mucosa formada por músculo liso. Submucosa formada por tecido conjuntivo frouxo e apresentou-se bastante vascularizada (Fig.2L). A camada muscular estava subdividida em duas camadas, uma camada muscular circular interna formada por músculo liso contínuo, e uma camada muscular longitudinal externa (Fig.2M).

\section{DISCUSSÃO}

Estudos morfológicos em tartarugas marinhas ainda são escassos, existindo pouca bibliografia sobre o assunto, 0 que torna necessário mais estudos nessa área, no intuito de assentar bases morfológicas para pesquisas aplicadas posteriores. Estudos de parâmetros morfométricos e morfológicos do trato gastrintestinal se fazem necessários para fornecer subsídios sobre os processos digestórios dos alimentos no organismo animal e indicar a preferência alimentar de uma espécie (Luz et al. 2003).

O esôfago é um órgão tubular que tem como principal função transportar o conteúdo alimentar da boca para o estômago. Já foi demonstrado por outros autores (Porter 1972, Parsons \& Cameron 1977, Work 2000, Wyneken 2001, Pressler et al. 2003) que a mucosa esofágica das tartarugas marinhas apresenta papilas pontiagudas córneas, as quais possuíam a função mecânica de facilitar a deglutição e evitar o refluxo do alimento. Segundo Parsons \& Cameron (1977), essas papilas encontradas nas tartarugas marinhas são únicas entre os répteis. Nossos resultados confirmam a presença destas papilas em todos os animais estudados, porém observamos que seu tamanho e distribuição variaram ao longo do esôfago, tornando-se gradativamente maiores na direção da região caudal do esôfago, porém desaparecendo na transição do esôfago com o estômago, onde se encontrou o esfíncter gastresofágico, o qual também já havia sido descrito por outros autores (Work 2000, Wyneken 2001, Pressler et al. 2003).

No presente trabalho, esôfago da tartaruga verde apresentou-se desprovidos de glândulas, indicando mais uma vez que esse órgão apresenta apenas função mecânica nesta espécie. Achados semelhantes foram descritos por Santos et al. (1998) para tartaruga-da-amazônia (Podocnemis expansa) e por Vogt et al. (1998) para espécies de quelônios da família Pelomedusidae.

Para répteis, em geral, George \& Castro (1998), descreveram que a mucosa esofágica é revestida por epitélio com uma ou duas camadas de células colunares ou cuboidais ciliadas, entretanto, Santos et al. (1998), descrevem que o esôfago da tartaruga-da-amazônia (Podoc- 
nemis expansa) possuía mucosa pregueada revestida por um epitélio estratificado prismático, enquanto Vogt et al. (1998), em estudo realizado quelônios da família Pelomedusidae descreveu que possuíam epitélio estratificado pavimentoso. As tartarugas verdes analisadas neste trabalho apresentaram o mesmo padrão descrito por Vogt et al. (1998). O epitélio estratificado na mucosa esofágica de tartarugas, certamente tem função de proteger a mucosa esofágica contra atritos decorrentes da passagem do alimento pelo esôfago (Silva 2005). A presença de queratina também esta relacionada com essa função, no qual foi encontrada tanto no esôfago como nas papilas esofágicas nos animais estudados não sendo descrito por nenhum dos autores supracitados. A histologia das papilas esofágicas não havia sido descrita anteriormente.

Em espécimes de $C$. mydas foi observada uma especialização do esôfago, um divertículo. Tal achado havia sido descrito apenas por Work (2000) em tartarugas verdes do Hawai e por Wyneken (2001) em tartarugas verdes do pacífico. Segundo Work (2000) esta estrutura tem com função armazenar o alimento antes de passar para o estômago. Ainda nesse raciocínio, Ricklefs (2003) afirma que regiões alargadas do esôfago com forma de saco, funcionam como reservatórios ou câmaras de fermentação, com essas adaptações, o herbívoro pode manter refeições no trato digestório por mais tempo e digeri-las mais completamente.

A forma do estômago está intimamente relacionada com o tipo de dieta do animal (Work 2000, Romer \& Parsons 1985). Segundo Hildebrand (1995), os répteis carnívoros têm um estômago mais simples e a maioria dos répteis herbívoros tem um estômago mais complexo, que funcionam como reservatório ou câmara fermentativa. Em tartarugas carnívoras da espécie Dermochelys coriacea, o estômago apresentou forma tubular retilínea (Parsons \& Cameron 1977). No presente trabalho, as tartarugas verdes possuíram com aspecto saculiforme em forma de "J". Microscopicamente, no estômago das $C$. mydas analisadas foram observadas glândulas apenas na lâmina própria, conforme descrito por George \& Castro (1998) para os répteis e por Santos et al. (1998) para tartaruga-daamazônia. As fossetas gástricas presentes em $C$. mydas analisadas, no presente trabalho, estiveram dispostas por toda a mucosa gástrica, diferenciando na profundidade, sendo mais profundas na região pilórica e mais rasas na cárdica. Esse padrão está de acordo com Junqueira \& Carneiro (1999) para mamíferos, segundo esse autor as glândulas se abrem no fundo dessas fossetas. A camada muscular do estômago, diferentemente do observado no esôfago, apresentou duas camadas, uma interna com fibras musculares lisas orientadas circularmente, e outra externa, com fibras orientadas longitudinalmente, conforme padrão descrito por George \& Castro (1998) para répteis em geral. Entretanto, ocorreram diferenciações na camada muscular circular interna de cada região, onde a região cárdica e a fúndica apresentaram as fibras lisas agrupadas formando blocos de musculatura lisa separados por tecido conjuntivo frouxo, enquanto na pilórica foi observado fibras colágenas dispostas em septos que se ramificaram entre as fibras musculares lisas. Segundo Snell (1985) e Junqueira \& Carneiro (1999), as fibras colágenas são importantes mecanicamente, pois são flexíveis, mas fortemente resistentes as forças de tração. Função importante, já que toda a força do peristaltismo se dirige para a região pilórica. Possivelmente, essas diferenças estão relacionadas com as funções de cada região.

Nós observamos variações no padrão de distribuição das pregas da mucosa nas diversas porções do intestino delgado da tartaruga verde. Diferente dos achados descritos por Work (2000) e Wyneken (2001) ao afirmarem que toda a mucosa desta porção do intestino possuía pregas reticulares com aparência de "favos de mel". O que pode prejudicar a analise é a difícil identificação e delimitação da transição entre as regiões do intestino, onde para confirmação, o ideal é utilizar métodos histológicos. Apesar do que nas tartarugas estudadas nesse trabalho a delimitação do duodeno para o jejuno foi de fácil visualização, devido à mudança na mucosa, onde o duodeno encontrava-se marcado com pregas reticulares, do jejuno para o íleo não foi possível fazer a distinção, pois ambos possuíam pregas retilíneas. Histologicamente, nos animais analisados as três porções (duodeno, jejuno e íleo) apresentaram a mucosa constituída por vilosidades, estando de acordo com Junqueira \& Carneiro (1999) para mamíferos e com Santos et al. (1998) para tartaruga-da-amazônia, porém George \& Castro (1998) descreveram que para as tartarugas ocorriam elevadas dobras, não sendo consideradas vilosidades. Nas tartarugas marinhas analisadas essas vilosidades apresentaram-se longas e filiformes no duodeno, curtas e digitiformes no jejuno e foliadas no íleo. A forma das vilosidades foi descrito por Junqueira \& Carneiro (1999) para mamíferos com sendo foliada no duodeno e no íleo assumiam um aspecto digitiforme, não estando de acordo com o descrito para as espécies do presente trabaIho. De acordo com Romer \& Parson (1985), Junqueira \& Carneiro (1999), a presença de pregas, vilos e microvilos aumentam sobremodo a superfície da parede intestinal, importantes características de um órgão onde ocorre tão intensa absorção.

A transição do íleo para o intestino grosso foi evidente devido à presença de um esfíncter muscular (Romer \& Parsons 1985), denominado de válvula ileocecal por Porter (1972), Rainey (1981), Wyneken (2001). Quanto às especializações da mucosa do intestino grosso, os autores defendem a ausência de pregas em tartarugas marinhas (Work 2000) semelhantes achados foram observados nas espécies estudadas presente trabalho. Histologicamente, o intestino grosso nas tartarugas verdes estudadas apresentou mucosa pregueada contendo glândulas e acúmulo de linfócitos na lâmina própria. A presença de pregas foi descrita para répteis por George \& Castro (1998) e por Silva (2005) para alguns cortes da espécie Steindachnerina notonota, entretanto para mamíferos Junqueira \& Carneiro (1999) descreveram que a mucosa era lisa, sem pregas, exceto na porção retal. A presença de glândulas e de linfó- 
citos também foi descrita pelos dois autores citados acima. A riqueza em células do sistema imunitário deve estar relacionada com a variedade e abundante população bacteriana no intestino grosso (Junqueira \& Carneiro 1999).

Especializações na mucosa do intestino, como a presença de pregas, estão relacionadas com aumento da capacidade absortiva dos nutrientes em função da maior superfície de contato da mucosa (Porter 1972, Fugi \& Hahn 1991, Wyneken 2001). Isso explica, portanto, o fato do intestino delgado apresentar pregas na mucosa e o intestino grosso não, já que o primeiro tem como principal função a maior absorção de nutrientes.

Stevens \& Hume (1998) afirmam que o intestino delgado tende a ser o mais longo nos carnívoros e o mais curto nos herbívoros. Nossos resultados confirmam essas afirmações, pois de acordo as análises morfométricas dos órgãos do tubo digestório das tartarugas verdes analisadas o comprimento do intestino grosso foi maior que o intestino delgado. Essas diferenças no comprimento do intestino delgado e do grosso são explicadas pelo fato de que os alimentos de origem animal são mais facilmente digeridos do que os de origem vegetal (Ricklefs 2003).

\section{CONCLUSÕES}

A morfologia do tubo digestório da tartaruga verde mostrou-se adaptado ao seu hábito alimentar, possuindo especializações e um longo trato digestório que promove o aumento da superfície de absorção, já que seu alimento é de difícil digestão. Dentre estas especializações, destacamos a presença de epitélio estratificado pavimentoso queratinizado na mucosa esofágica como proteção contra atritos decorrentes da passagem do alimento; mucosa esofágica marcada por papilas córneas macroscópicas orientadas no sentido caudal (do estômago) para facilitar a deglutição e evitar o refluxo do alimento nestes animais de ambiente marinho; divertículo esofágico que funciona como reservatório ou câmara de fermentação; padrão de pregueamento e das vilosidades que variam ao longo da mucosa intestinal para garantindo maior área de contato; e comprimento médio do intestino grosso maior que do intestino delgado.

\section{REFERÊNCIAS}

Bjorndal K.A. 1997. Foraging ecology and nutrition of sea turtle, p.199231. In: Lutz P.L. \& Musick J.A. (Eds), The Biology of Sea Turtle. Marine Science Series, New York.

Bolten A.B. 2000. Técnicas para la medición de tortugas marinas, p.126-131. In: Eckert K.L., Bjorndal K.A., Abreu-Grobois F.A. \& Donnelly M. (Eds), Técnicas de Investigación y Manejo para la Conservación de las Tortugas Marinas. Publicación no 4, UICN/CSE Grupo Especialista de Tortugas Marinas, Washington, USA.

Brand-Gardner S.J., Lanyon J.M. \& Limpus C.J. 1999. Diet selection by immature green turtles, Chelonia mydas, in subtropical Moreton Bay, South-East Queensland. Aust. J. Zool. 47:181-191.

Castell E.D., López-Mendilaharsu M. \& Izquierdo G. 2005. Hábitos Alimentarios de Juveniles de Tortuga Verde (Chelonia mydas) en Cerro Verde, Rocha-Uruguay. Anais II Jornada de Conservação e Pesquisa de Tartarugas Marinhas no Atlântico Sul Ocidental, Praia do Cassino, Brasil, p.15-18.
Chevalier J. \& Lartiges A. 2001. Les Tortues Marines des Antilles. Ed. Office National de La Chasse et de la Faune Sauvage. CNERA Faune d'Outre Mer, Paris. 59p.

Costa F.B., Alves F.R., Costa A.P., Barros A.C.E., Guerra P.C., Sousa A.L. \& Oliveira A.S. 2009. Determinação ultrassonográfica e radiográfica do desenvolvimento de ovos de jurarás em cativeiro. Pesq. Vet. Bras. 29(10):841-846.

Ferreira M.M. 1968. Sobre a alimentação da aruana, Chelonia mydas Linnaeus, ao longo da costa do estado do Ceará. Arq. Est. Biol. Mar. Univ. Fed. Ceará 8(1):83-86.

Fidelis S.V., Ballabio T.A. \& Guebert F.M. 2005. Análise da relação corporal do trato gastrointestinal da Chelonia mydas (tartaruga verde) juvenil do litoral do Paraná. Anais II Congr. Bras. Oceanografia, Vitória, p.1-3

Fugi R. \& Hahn N.S. 1991. Espectro alimentar e relações morfológicas com o aparelho digestivo de três espécies comedores de fundo do rio Paraná, Brasil. Revta Bras. Biol. 51(4):873-879.

George L.L. \& Castro R.R.L. 1998. Histologia Comparada. $2^{\text {a }}$ ed. Roca, São Paulo. 286p.

Hildebrand M. 1995. Analise da Estrutura dos Vertebrados. $3^{\mathrm{a}}$ ed. Atheneu, São Paulo. 700p.

Holt P.E. 1978. Radiological studies of the alimentary tract in two Greek tortoises (Testudo graeca). Vet. Rec. 103(10):198-200.

Junqueira L.C. \& Carneiro J. 1999. Histologia Básica. 9ª ed. Guanabara Koogan, Rio de Janeiro. 478p.

Luz V.L.F., Stringhini J.H., Bataus Y.S.L., Paula W.A., Novais M.N. \& Reis I.J. 2003. Morfometria do trato digestório da tartaruga-daamazônia (Podocnemis expansa) criada em sistema comercial. Revta Bras. Zootec. 32(1):10-18.

Maia V. 1979. Técnica Histológica. $2^{\text {a }}$ ed. Atheneu, São Paulo, p.70-136. Meyer J. 1998. Gastrografin as a gastrointestinal contrast agent in the Greek tortoise (Testudo hermani). J. Zoo Wildl. Med. 29(2):183-189.

MMA 2005. Ministério do Meio Ambiente. Disponível em: http://www. mma.gov.br/port/sbf/fauna. Acesso em 15 jun. 2005.

Marcovaldi M.A. \& Marcovaldi G.G. 1985. Projeto Tamar: área de desova, ocorrência e distribuição das espécies, época de reprodução, comportamento de postura e técnicas de conservação das tartarugas marinhas no Brasil. IBDF, Min. Agricultura, Brasília. 46p.

Parsons T.S. \& Cameron J.E. 1977. The internal relief of the digestive tract, p.159-223. In: Gans G. \& Parsons T.S. (Eds), Biology of the Reptilia. Academic Press, New York.

Pessoa C.A., Rodrigues M.A., Kozu F.O., Prazeres R.F. \& Fecchio R.S. 2008. Ooforectomia videoassistida por acesso pré-femural em tartaruga-de-ouvido-vermelho (Trachemys scripta elegans). Pesq. Vet. Bras. 28(7):345-349

Pinto J.G.S. 2006. Aspectos Anátomo-radiográficos e tempo de trânsito gastrintestinal em tracajá Podocnemis unifilis Troschel, 1848 (Testudines, Podocnemididae). Dissertação de Mestrado, Curso de Pós-Graduação em Ciências Veterinárias, Universidade Federal de Uberlândia. 34p.

Porter K.R. 1972. Herpetology. W.B. Saunders Company, Canada. 530p.

Pressler B.M., Goodman R.A., Harms C.A., Hawkins E.C \& Lewbart G.A. 2003. Endoscopic evaluation of the esophagus and stomach in three loggerhead sea turtles (Caretta caretta) and a Malaysian giant turtle (Orlitia borneensis). J. Zoo Wildl. Med. 34(1):88-92.

Rainey W.E. 1981. Guide to Sea Turtle Visceral Anatomy. NOAA Technical Memorandum NMFS-SEFC, University of California, Berkeley. 80p.

Ricklefs R.E. 2003. A Economia da Natureza. $5^{\mathrm{a}}$ ed. Guanabara Koogan, Rio de Janeiro. 503p.

Romer A.S. \& Parsons T.S. 1985. Anatomia Comparada dos Vertebrados. 5a ed. Atheneu, São Paulo. 559p. 
Sanches T.M. 1999. Avaliação e ações prioritárias para a conservação da biodiversidade da zona costeira e marinha: tartarugas marinhas. Termo de Referência no155/98. Disponível em: http:// www.bdt.org.br/workshop/costa/tartaruga/diagnostico. Acesso em 22 fev. 2007

Santos A.L.Q., Beletti M.E. \& Queiroz R.P. 1998. Estudo morfológico do tubo digestivo da tartaruga-da-amazônia Podocnemis expansa. Relatório, Universidade Federal de Uberlândia, Uberlândia. 15p.

Santos A.J.B., França B.R.A. \& Bellini C. 2006. Registro de predação de ovos e neonatos de Eretmochelys imbricata no litoral sul do Rio Grande do Norte. Anais XXVI Congr. Bras. Zoologia, Londrina.

Seminoff J.A., Resendiz A. \& Nichols Y.W.J. 2002. Diet of the east Pacific Green Turtle, Chelonia mydas, in the central Gulf of California, Mexico. J. Herpetology. 36:447-453.

Silva N.B. 2004. Estudo morfohistológico do tubo digestório de Steindachnerina notonota Ribeiro 1937 (Characiforme, Curimatidae) e Hoplias malabaricus Bloch 1794 (Characiformes, Erythrinidae) do rio Ceará-Mirim em Umari, Distrito de Taipu-RN. Dissertação de Mestrado, Curso de Pós-Graduação em Bioecologia aquática, Universidade Federal do Rio Grande do Norte, Natal. 62p.

Silva N.B. 2005. Histologia do sistema digestório de sagüiru, Steinda- chnerina notonota (Miranda Ribeiro 1937) (Pisces, Curimatidae), do rio Ceará-Mirim, Rio Grande do Norte, Brasil. Bolm Inst. Pesca 31(1):18.

Silva P.F., Magalhães M.S., Santos A.J.B., Coluchi R., Silva N.B. \& Moura C.E.B. 2007. Presença de lixo no tubo digestório de tartarugas marinhas no litoral do Rio Grande do Norte e possíveis lesões decorrentes desta contaminação. Anais $10^{\circ}$ Simpósio de Biologia Marinha, Santos.

Snell R.S. 1985. Histologia Clínica. Interamericana, Rio de Janeiro. $686 \mathrm{p}$.

Stevens C.E. \& Hume I.D. 1998. Contributions of microbes in vertebrate gastrointestinal tract to production and conservation of nutrients. Physiol. Rev. 78(2):393-427.

Vogt R.C., Sever D.M. \& Moreira G. 1998. Esophageal papillae in Pelomedusid turtles. J. Herpetology 32(2):279-282.

Work T.M. 2000. Manual de Necropsia de Tortugas Marinas para Biologos en Refugios o Areas Remotas. National Wildlife Health Center, Hawaii Field Station. 25p.

Wyneken J. 2001.The Anatomy of Sea Turtles. NOAA Technical Memorandum NMFS-SEFSC-470, US Department of Commerce, Washington.DC. 172p. 